\title{
Chromosome polymorphism in the Brazilian dwarf brocket deer, Mazama nana (Mammalia, Cervidae)
}

\author{
Vanessa Veltrini Abril ${ }^{1,2}$ and José Maurício Barbanti Duarte ${ }^{2}$ \\ ${ }^{1}$ Programa de Pós-Graduação em Genética e Melhoramento Animal, Faculdade de Ciências Agrárias \\ e Veterinárias, Universidade Estadual Paulista, Campus de Jaboticabal, Jaboticabal, SP, Brazil. \\ ${ }^{2}$ Núcleo de Pesquisa e Conservação de Cervídeos, Departamento de Zootecnia, Faculdade de Ciências \\ Agrárias e Veterinárias, Universidade Estadual Paulista, Campus de Jaboticabal, Jaboticabal, SP, Brazil.
}

\begin{abstract}
The Brazilian dwarf brocket deer (Mazama nana) is the smallest deer species in Brazil and is considered threatened due to the reduction and alteration of its habitat, the Atlantic Rainforest. Moreover, previous work suggested the presence of intraspecific chromosome polymorphisms which may contribute to further population instability because of the reduced fertility arising from the deleterious effects of chromosome rearrangements during meiosis. We used Gand $\mathrm{C}$-banding, and nucleolus organizer regions localization by silver-nitrate staining (Ag-NOR) to investigate the causes of this variation. Mazama nana exhibited eight different karyotypes ( $2 n=36$ through 39 and FN $=58)$ resulting from centric fusions and from inter and intraindividual variation in the number of B chromosomes (one to six). Most of the animals were heterozygous for a single fusion, suggesting one or several of the following: a) genetic instability in a species that has not reached its optimal karyotypic evolutionary state yet; b) negative selective pressure acting on accumulated rearrangements; and c) probable positive selection pressure for heterozygous individuals which maintains the polymorphism in the population (in contrast with the negative selection for many rearrangements within a single individual).
\end{abstract}

Key words: Mazama nana, Brazilian dwarf brocket deer, cytogenetics, chromosome polymorphism, centric fusions.

Received: June 28, 2007; Accepted: October 16, 2007.

\section{Introduction}

The genus Mazama (Artiodactyla, Cervidae) is composed of eight species: M. rufina, M. pandora, M. chunyi, $M$. americana, $M$. gouazoubira, $M$. nana, $M$. nemorivaga and M. bororo (Wemmer, 1998; Duarte, 2007). It is distributed from Mexico to central Argentina and is classified as a "small solitary forest deer" because of its ecological and behavioral characteristics (Barrette, 1987; Eisenberg \& Redford, 1999). In Brazil, five species are recognized based on morphology and cytogenetics: M. gouazoubira, $M$. nemorivaga, $M$. americana, $M$. nana and $M$. bororo (Duarte \& Merino, 1997; Duarte \& Jorge, 2003; Duarte, 2007).

The Brazilian dwarf brocket (Mazama nana) is the smallest deer species in Brazil, reaching a weight of $15 \mathrm{~kg}$ and a height of $45 \mathrm{~cm}$. This species has small, slightly pointed and almost hairless ears and displays little gradation in its reddish coloration, other than a few white hairs on

Send correspondence to José Maurício Barbanti Duarte. Departamento de Zootecnia, Faculdade de Ciências Agrárias e Veterinárias, Universidade Estadual Paulista, 14884-900 Jaboticabal, SP, Brazil. E-mail: barbanti@fcav.unesp.br. the tail. Its anterior limbs are shorter and darker than the posterior ones (Duarte, 1996; Mikich \& Bérnils, 2004). Mazama nana is found from northern Paraná State to central Rio Grande do Sul State, encompassing parts of Paraguay and Argentina. These areas are presently undergoing significant fragmentation and anthropic alteration (Duarte, 1996). The Brazilian dwarf brocket deer was identified as vulnerable in the official list of Brazilian threatened species in 2003 following the recommendation of the Deer Specialist Group and was classified as DD (deficient data) in "The 2006 IUCN Red List” (IUCN, 2006; IBAMA, 2007).

The $M$. nana karyotype was initially described from analyses of three animals from the Paraná River basin in the Foz do Iguaçu region. These individuals possessed $2 \mathrm{n}=36$ and $\mathrm{FN}=58$ with four or five B chromosomes. Chromosomes $1,2,6,7,8,9$ and 10 were metacentric; chromosomes 3, 4 and 5 were submetacentric; chromosomes 11 through 17 were acrocentric; the $\mathrm{X}$ chromosome was a midium-sized metacentric and the $\mathrm{Y}$ was probably a smallsized metacentric. A karyotype with $2 \mathrm{n}=39+5 \mathrm{~B}$ and $\mathrm{FN}=58$, heterozygous for a centric fusion involving pair 5 and lacking the metacentric pair 10 was also described 
(Duarte JMB, Aspectos taxonômicos e citogenéticos de algumas espécies de cervídeos brasileiros. Master's thesis. Faculdade de Ciências Agrárias e Veterinárias/Universidade Estadual Paulista, 1992). More recently, chromosome polymorphisms were described in animals from different localities of Brazil (Paraná, Santa Catarina and Rio Grande do Sul States) and Paraguay in which the diploid number varied from 36 to 40 , the FN ranged from 56 to 60 and there were up seven B chromosomes (Duarte JMB, Análise citogenética e taxonômica do gênero Mazama (Cervidae; Artiodactyla) no Brasil. PhD thesis, Instituto de Biociências, Universidade Estadual Paulista, 1998). As no banding patterns were obtained, the cause of this variation was not clearly ascertained and it was suggested to result from chromosome fusions/fissions.

The aim of the present study was to use G- and C-banding and Ag-NOR to identify individual chromosomes and the rearrangements involved in the polymorphisms described in Mazama nana.

\section{Material and Methods}

After physical and chemical restraint of the animals, blood and skin samples were collected from 24 captive Mazama nana (13 males and 11 females) and used to obtain chromosome preparations after lymphocyte and fibroblasts cultures (Verma \& Babu, 1995). G- and C-banding and Ag-NOR were obtained according to Seabright (1971), Sumner (1972) and Howell \& Black (1980), respectively.

The chromosomes were classified as metacentric, submetacentric or acrocentric according to their arms ratio and were organized into groups according to their relative lengths (RL): A (biarmed chromosomes with RL $>2.5 \%$ ), $\mathrm{C}$ (biarmed chromosomes with RL $>2.5 \%$ ), D (acrocentric chromosomes with RL $<3.0 \%$ ), E (acrocentric chromosomes with $\mathrm{RL}>3.0 \%$ ) and $\mathrm{B}$ (microchromosomes or extranumerary chromosomes with RL $>1.0 \%$ ). B chromosomes were not considered to calculate the diploid and fundamental numbers because there was intraindividual variation.

\section{Results and Discussion}

The diploid number varied from $2 \mathrm{n}=36$ to 39 with $\mathrm{FN}=58$ and seven distinct karyotypes were found due to several rearrangements (V01 to V07; Table 1). The X chromosome was a medium-sized metacentric and the $\mathrm{Y}$ was possibly a small-sized metacentric.

The most frequent karyotype (V01) showed $2 \mathrm{n}=36$ and one to six $\mathrm{B}$ chromosomes and $\mathrm{FN}=58$, with six, four and seven chromosome pairs in groups $\mathrm{A}, \mathrm{C}$ and $\mathrm{E}$, respectively (Figure 1). This karyotype was composed of six metacentric (pairs 1, 3, 6, 7, 8 and 10), four submetacentric (pairs 2, 4, 5 and 9) and seven acrocentric (pairs 11 to 17) autosome pairs. This karyotype is the same presented by Duarte (PhD thesis, 1992) and the differences between both

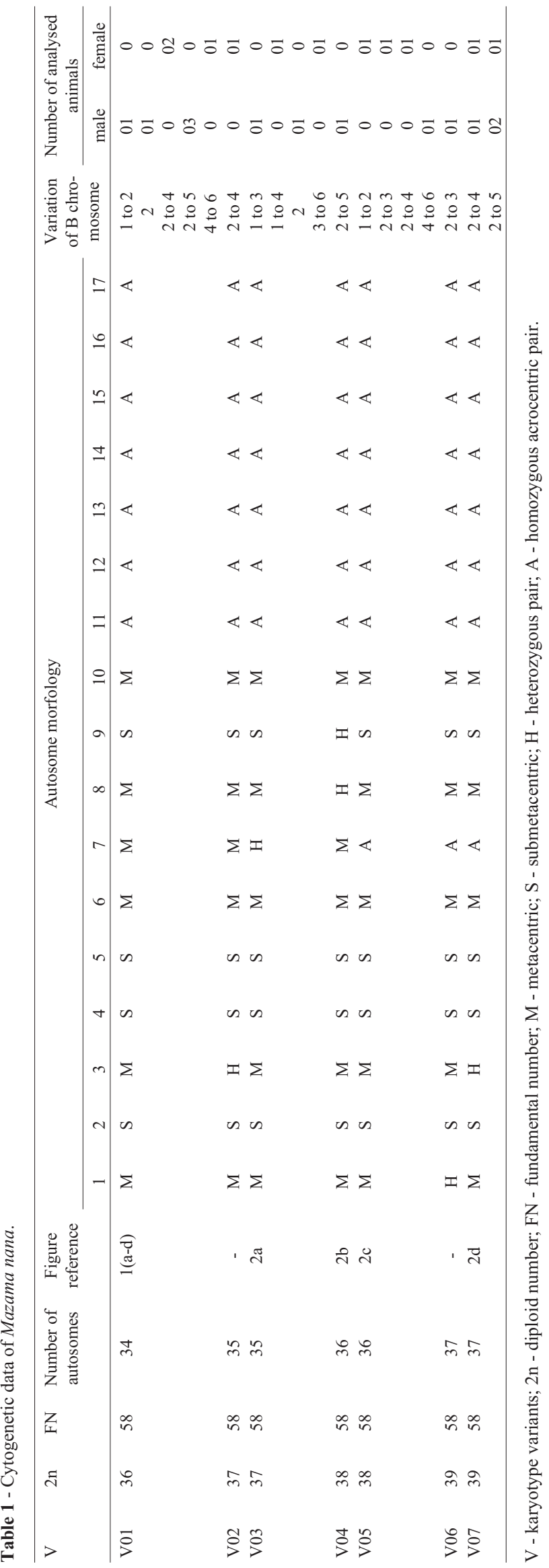




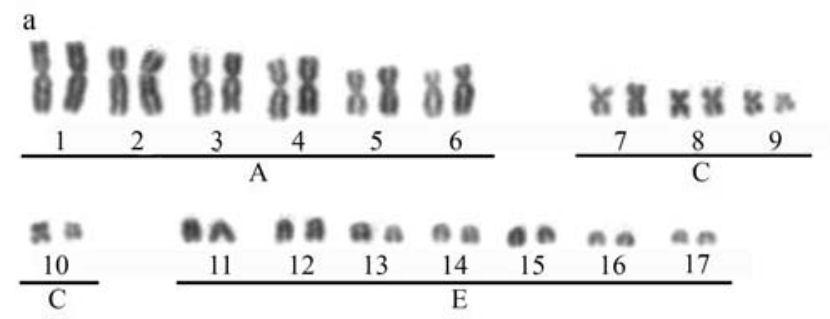

b
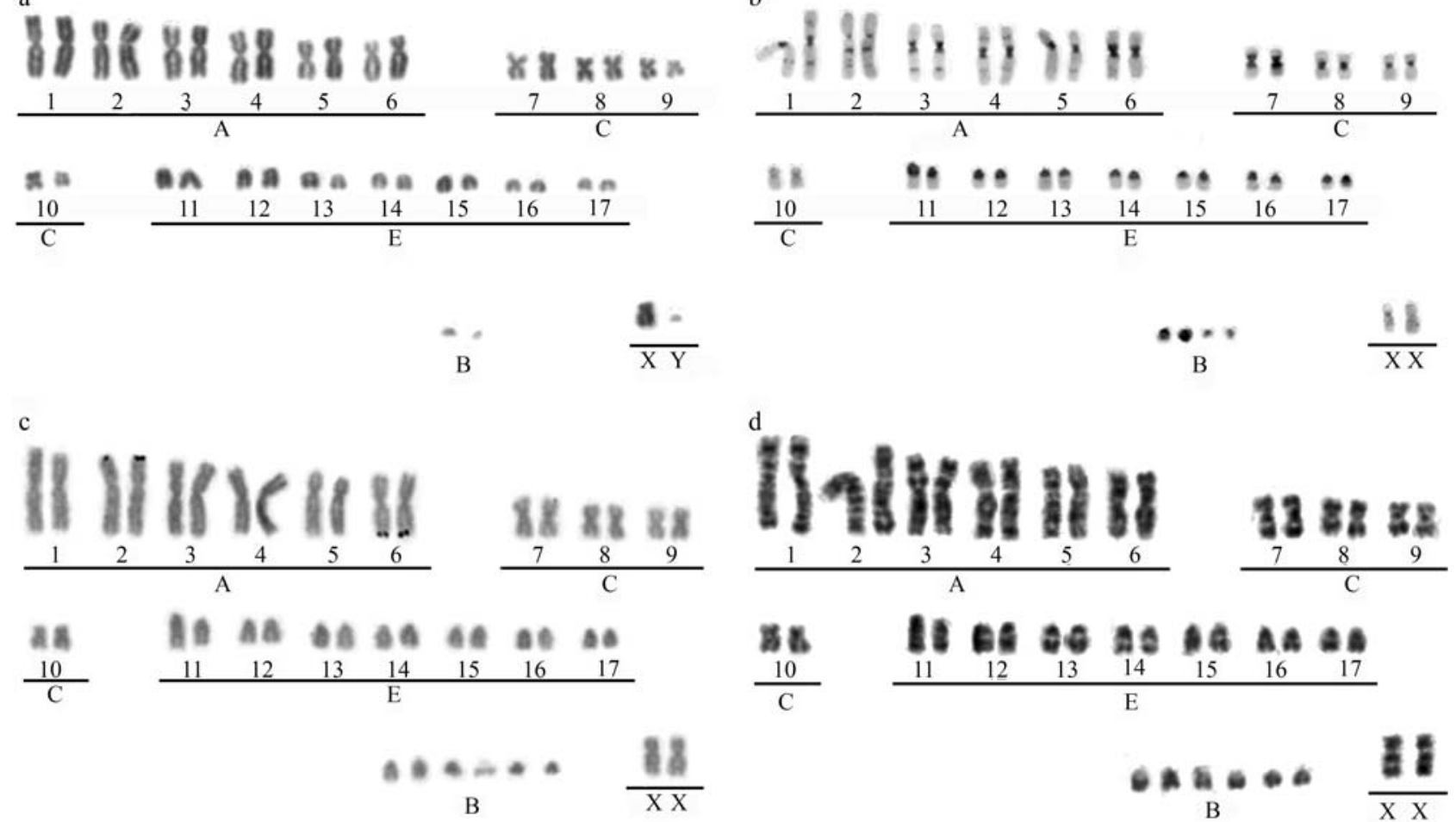

Figure 1 - Karyotype V01 of Mazama nana ( $2 \mathrm{n}=36$; FN = 58) after (a) conventional Giemsa staining, (b) C-banding, (c) Ag-NOR staining and (d) G-banding.

classifications are due to chromosome ordering. All chromosome pairs, except pairs 2 and 10, presented pericentromeric constitutive heterochromatin after C-banding. Pairs 2 and 10 showed a faint positive C-band in the centromere. Interstitial hetrochromatin was detected in both chromosome arms of pairs 1 and 4 and on the long arm of pairs 2,3 and 5 (Figure 1b). The Ag-NORs were terminally located on the short arms of pair 2 and on the long arms of pair 6 (Figure 1c). G-banding allowed the identification of all chromosomes (Figure 1d).

V01 $(2 \mathrm{n}=36+1$ to $6 \mathrm{~B} ; \mathrm{FN}=58)$ was chosen as the standard karyotype for the species based on its higher frequency among the animals analyzed ( 8 out of 24 ) and on the literature of cervid ancestral karyotypes. The current hypothesis is that chromosome evolution in Cervidae primarily occurred through centric and tandem fusions. This is the case of Muntiacus, in which the divergence from the ancestral karyotype has been shown to be due to different combinations of several centric and tandem fusions (Neitzel, 1987; Fontana \& Rubini, 1990; Lin et al. 1991; Lee et al. 1993; Yang et al. 1995; Yang et al. 1997).

V02 and V03 shared the same diploid and fundamental numbers $(2 \mathrm{n}=37 ; \mathrm{FN}=58)$, but while V02 was heterozygous for a centric fusion in pair 3, V03 was heterozygous for a centric fusion in pair 7 (Figure 2a). The number of $B$ chromosomes varied from two to four in V02 and from one to six in V03.
V04 $(2 \mathrm{n}=38+2$ to $5 \mathrm{~B} ; \mathrm{FN}=58)$ was the only karyotypic variant with two heterozygous rearrangements involving pairs 8 and 9 . V05 also presented $2 \mathrm{n}=38$ and $\mathrm{FN}=58$, but had an acrocentric pair 7 (Figures 2c, 2d) and one to six B chromosomes.

V06 and V07 shared the same diploid and fundamental numbers $(2 \mathrm{n}=39 ; \mathrm{FN}=58)$ and the absence of the metacentric pair 7, represented by identifiable acrocentric chromosomes. These two karyotypes differed in the chromosome pairs involved in heterozygous centric fusions, pair 1 in V06 and pair 3 in V07 (Figure 2d). The number of $\mathrm{B}$ chromosomes varied from two to three in V06 and from two to five in V07.

The hypothetical ancestral karyotype of Cervidae is exclusively composed of acrocentric chromosomes and the karyotypic evolution in cervids is believed to have primarily resulted from chromosome fusions with reduction of the diploid number (Neitzel, 1987, Duarte \& Merino, 1997). The existence of heterozygous karyotypic variants in the Brazilian dwarf brocket deer may be an indication of a recent karyological evolution.

In addition to chromosome polymorphisms in the normal complement, there were inter- and intraindividual variations in the number of $\mathrm{B}$ chromosomes, which ranged from one to six and were classified as acrocentric with RL $>1.5 \%$ (Table 1). Some B chromosomes were euchromatic, others were completely heterochromatic and some showed positive $\mathrm{C}$-banding in the pericentromeric region. 


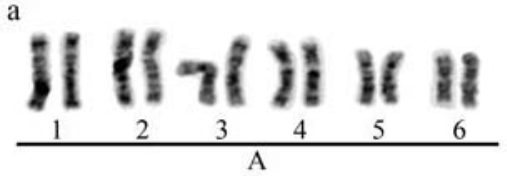

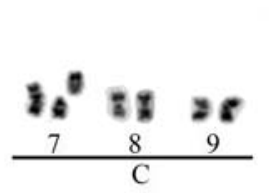
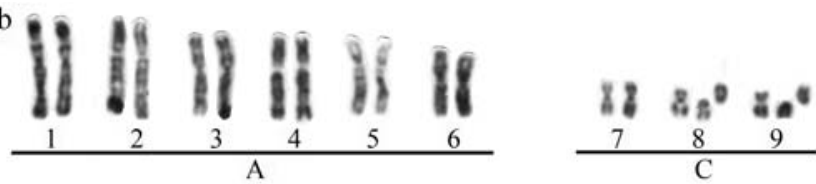

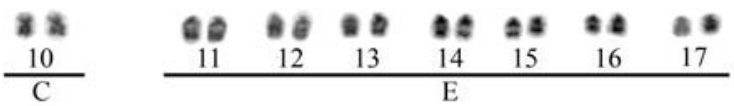
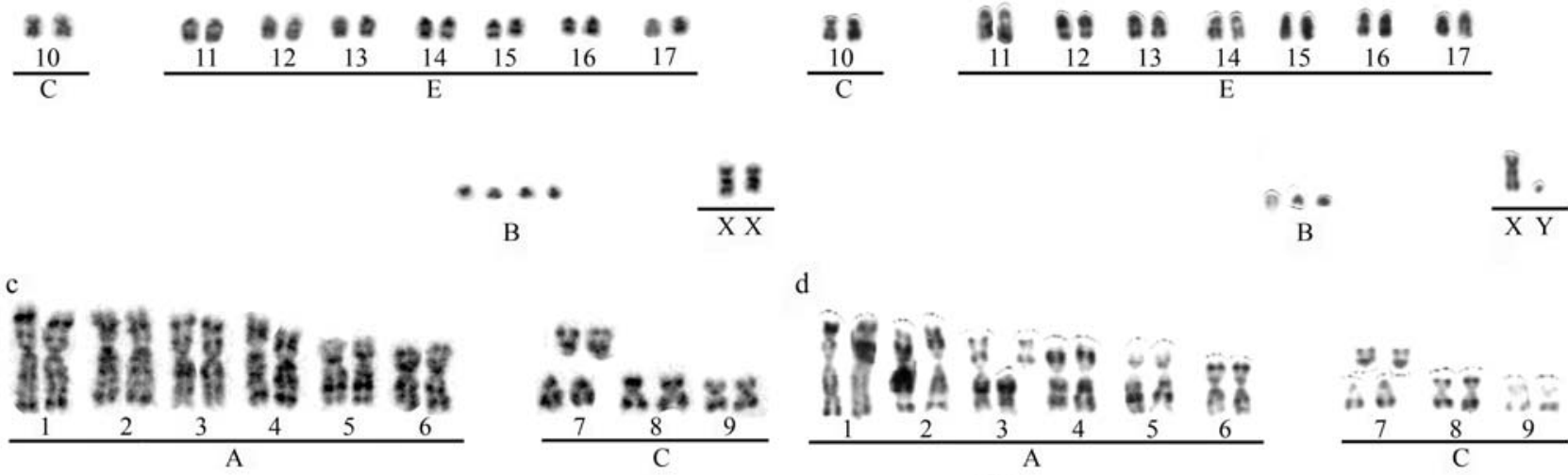

d
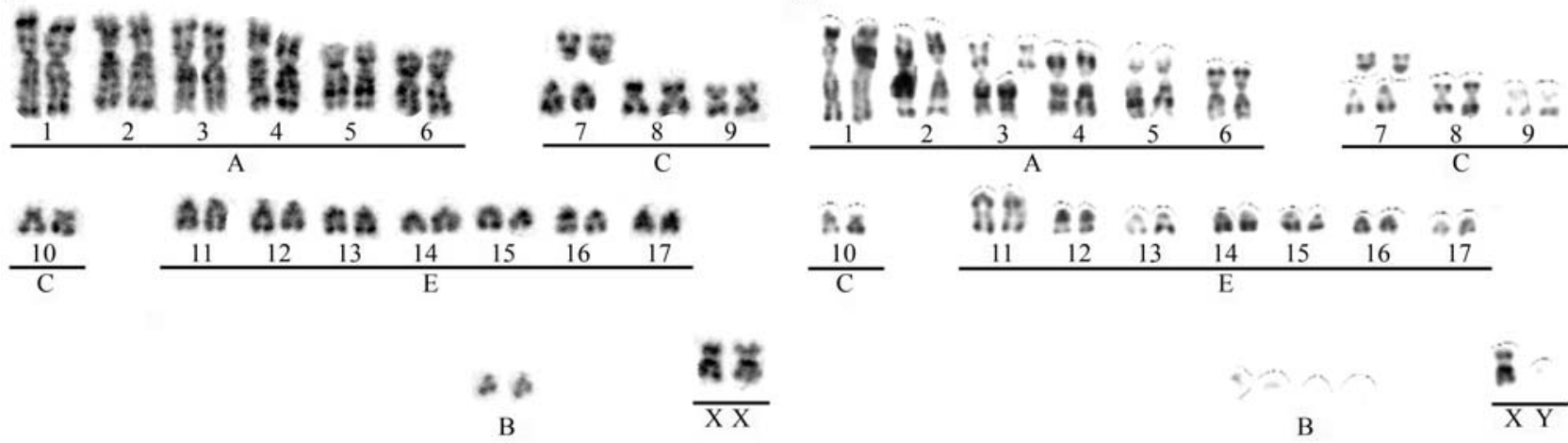

Figure 2 - G-banded karyotypes of Mazama nana: (a) V03, pair 7 is heterozygous for a centric fusion $(2 \mathrm{n}=37+4 \mathrm{~B}$; FN = 58); (b) V04, pairs 8 and 9 are heterozygous for centric fusions $(2 \mathrm{n}=38+3 \mathrm{~B}$; $\mathrm{FN}=58)$; (c) V05, pair 7 is acrocentric $(2 \mathrm{n}=38+2 \mathrm{~B}$; FN $=58)$; $(\mathrm{d}) \mathrm{V} 07$, pair 3 is heterozygous for a centric fusion and pair 7 is acrocentric $(2 \mathrm{n}=39+4 \mathrm{~B} ; \mathrm{FN}=58)$.

Moreover, there were $\mathrm{B}$ chromosomes that showed positive G-banding in the telomere region. B chromosomes have a heterogeneous behavior and there are many theories to explain their constitution. According to Palestis et al. (2004), heterochromatic B chromosomes could originate from Robertsonian fusions involving biarmed chromosomes which lose centromeric fragments that occasionally behave like B chromosomes or from the amplification of the paracentromeric region of a fragmented A chromosome. Nevertheless, the B chromosomes of Apodemus flavicollis are euchromatic and the application of differential staining showed homology in the distribution of G- and C-bands between the A and B chromosomes, suggesting that they directly derived from the A set (Tanic et al., 2005).

Intraspecific karyotypic variation appears to be common among Cervidae (Herzog \& Harrington, 1991; Duarte \& Jorge, 1996). Given that the intraspecific variation is primarily generated by Robertsonian translocations, Herzog and Harrington (1991) proposed two hypotheses to explain the origin and maintenance of populational polymorphisms: a) translocations are continuously generated by selectively neutral recent mutations and fixed due to the high endogamy level between social groups or b) polymorphism is generated by hybridization events between different taxa, which would result in Robertsonian polymorphisms in the hybrid populations. The first hypothesis seems more adequate to explain the results observed in the Brazilian dwarf brocket since no evidence of hybridization was observed. This hypothesis is strengthened by the higher chromosome fragility found in cervids of the Mazama genus (VargasMunar DSF, Relação entre fragilidade cromossômica e trocas entre cromátides irmãs com a variabilidade cariotípica de cervídeos brasileiros, Master's thesis. Faculdade de Ciências Agrárias e Veterinárias/UNESP, 2003).

Although six chromosome pairs appear to be involved in rearrangements, the majority of individuals analyzed were heterozygous for a single centric fusion and only one possessed two heterozygous pairs for this type of rearrangement. Since centric fusions may produce three possible chromosome arrangements (not fused, heterozygous or fused), there are theoretically 729 different combinations, from which only eight were observed. This may be a consequence of negative selection for the accumulation of rearrangements within individuals due to lower fertility in carriers of several heterozygous rearrangements which would present problems during meiotic pairing and germ cell death (Wallace et al., 2002). Conversely, it is probable that there is some adaptive advantage for fusions carriers since these remain in the population until they are fixed in the homozygous form, as occurs in V01 (the standard karyotype). The adaptive advantage generated by rearrangements could supersede the consequences of inefficient meiotic pairing. Nevertheless, it is evident that the species is undergoing intense chromosome evolution that 
can lead to adaptive deficiencies which, combined with pressures from habitat (Mixed Ombrophylous Forest) alteration, may lead to an unprecedented population decline.

Despite our detailed description of the chromosome variation in Mazama nana, a wider population sampling is necessary to understand the influence of chromosome polymorphisms in the dynamics of the remaining populations of this threatened species.

\section{Acknowledgments}

This study was supported by Fundação de Amparo à Pesquisa do Estado de São Paulo (FAPESP) and Conselho Nacional de Desenvolvimento Científico e Tecnológico (CNPq). The authors are grateful to Paulo Antonio Tosta and João Airton Boer for laboratory assistance.

\section{References}

Barrette C (1987) The comparative behavior and ecology of chevrotains, musk deer and morphologically conservative deer. In: Wemmer CM (ed) Biology and Management of the Cervidae. Smithsonian Institution Press, Washington D.C., pp 200-213.

Duarte JMB (1996) Guia de Identificação de Cervídeos Brasileiros. FUNEP, Jaboticabal, 14 pp.

Duarte JMB (2007) Artiodactyla - Cervidae. In: Cucas Z, Silva JCR and Catão-Dias JL (eds) Tratado de Animais Selvagens, Medicina Veterinária. Roca, São Paulo, pp 641-664.

Duarte JMB and Jorge W (1996) Chromosomal polymorphism in several populations of deer (genus Mazama) from Brazil. Arch Zootec 45:281-287.

Duarte JMB and Jorge W (2003) Morphologic and cytogenetic description of the small red brocket (Mazama bororo Duarte, 1996) in Brazil. Mammalia 67:403-410.

Duarte JMB and Merino ML (1997) Taxonomia e Evolução. In: Duarte JMB (ed) Biologia e Conservação de Cervídeos Sul-Americanos: Blastocerus, Ozotocerus e Mazama. FUNEP, Jaboticabal, pp 1-21.

Eisenberg JF and Redford KH (1999) Mammals of the Neotropics: The Central Neotropics. The University of Chicago Press, Chicago, 609 pp.

Fontana F and Rubini M (1990) Chromosomal evolution in Cervidae. BioSystems 34:157-174.

Herzog S and Harrington R (1991) The role of hybridization in the karyotype evolution of deer (Cervidae, Artiodactyla, Mammalia). Theor Appl Genet 82:425-429.

Howell WM and Black DA (1980) Controlled silver staining of nucleolus organizer regions with a protective colloidal developer: A 1-step method. Experientia 3:1014-1015.

Lee C, Sasi R and Lin CC (1993) Interstitial localization of telomeric DNA sequences in the Indian muntjac chromo- some: Further evidence for tandem chromosome fusions in the karyotypic evolution of the Asian muntjacs. Cytogenet Cell Genet 63:156-159.

Lin CC, Sasi R, Fan Y-S and Chen Z-Q (1991) New evidence for tandem chromosome fusions in the karyotype evolution of Asian muntjacs. Chromosoma 101:19-24.

Mikich SB and Bérnils RS (2004) Livro Vermelho da Fauna Ameaçada no Estado do Paraná. Instituto Ambiental do Paraná, Curitiba, 764 pp.

Neitzel H (1987) Chromosome evolution of Cervidae: Karyotypic and molecular aspects. In: Obe G and Basler A (eds) Cytogenetics, Basic and Applied Aspects. Springer Verlag, Berlin, pp 90-112.

Palestis BG, Burt A, Jones RN and Trivers R (2004) B chromosomes are more frequent in mammals with acrocentric karyotypes: Support for the theory of centromeric drive. Proc R Soc Lond B Suppl 271:S22-S24.

Seabright M (1971) A rapid banding technique for human chromosomes. Lancet. 1:971-972.

Sumner AT (1972) A simple technique for demonstrating centromeric heterochromatin. Exp Cell Res 75:304-306.

Tanic N, Vujosevic M, Denovic-Tanic N and Dimitrijevic B (2005) Differential gene expression in yellow-necked mice Apodemus flavicollis (Rodentia, Mammalia) with and without B chromosomes. Chromosoma 113:418-427.

Verma RS and Babu A (1995) Human Chromosomes: Principles and Techniques. 2nd ed. McGraw-Hill Inc., New York, 419 pp.

Wallace BMN, Searle JB and Everett CA (2002) The effect of multiple simple Robertsonian heterozygosity on chromosome pairing and fertility of wild-stock house mice (Mus musculus domesticus). Cytogenet Genome Res 96:276-286.

Wemmer C (1998) Deer-Status survey and Conservation Action Plan. IUCN/SSC Deer Specialist Group, Cambridge, 107 pp.

Yang F, Carter NP, Shi L and Ferguson-Smith MA (1995) A comparative study of karyotypes of muntjacs by chromosome painting. Chromosoma 103:642-652.

Yang F, O'Brien PCM, Wienberg J and Ferguson-Smith MA (1997) A reappraisal of the tandem fusion theory of karyotype evolution in the Indian muntajc using chromosome painting Chrom Res 5:109-117.

\section{Internet Resources}

IBAMA (2007) Lista Nacional das Espécies Brasileiras Ameaçadas de Extinção. http://www.mma.gov.br/port/sbf/fauna/ index.cfm (September 6, 2007).

IUCN (2006) The 2006 IUCN Red List of Threatened Species. http://www.iucnredlist.org (September 6, 2007).

Associate Editor: Yatiyo Yonenaga-Yassuda 